\title{
REPRESENTACIÓN E IDENTIDAD: LOS MUSEOS LOCALES EN LA PENÍNSULA DE SANTA ELENA EN LA COSTA ECUATORIANA
}

\author{
REPRESENTATION AND IDENTITY: LOCAL MUSEUMS IN THE SANTA ELENA \\ PENINSULA ON THE ECUADORIAN COAST
}

\author{
Ana Maritza Freire ${ }^{1}$
}

\begin{abstract}
La autopercepción de un "nosotros", sustentado en un pasado en común, construye una autoconcepción de identidad entre los comuneros peninsulares. Museos y patrimonio cultural articulados al conocimiento científico y arqueológico reconstruyen el pasado cultural y sustentan el presente. El carácter colectivo de la identidad cultural ha permitido garantizar la continuidad y permanencia en el tiempo de la sociedad comunal, y establece los límites en relación con su entorno social, definiendo quiénes son, con quiénes comparten y cómo se reconocen en su patrimonio. En este sentido, cada comunidad es un universo social que se asume como depositario de un acervo cultural que le ha sido heredado, en torno al cual forjan una identidad colectiva local, que se configura en contraste con el imaginario hegemónico de la identidad nacional. Esta presentación procura establecer diálogos entre interpretaciones arqueológicas con el reconocimiento y los significados atribuidos al patrimonio cultural, en comunas donde se erigieron museos como soporte de la revitalización cultural local y nacional.
\end{abstract}

Palabras claves: patrimonio, identidad, territorio, comunal, peninsular.

\begin{abstract}
The self-perception of a "we", anchored in a common past, creates a self-conception of identity among peninsular comuneros. Museums and cultural heritage connected with scientific and archaeological knowledge reconstruct the cultural past and support the present. The collective nature of cultural identity has guaranteed the continuity and permanence over time of the communal society, and sets limits in relation to its social surroundings, defining who they are, who they share with and how they see themselves in their heritage. In this respect, every community is a social universe that identifies itself as a holder of cultural heritage which has been transmitted to them, around which they create a collective local identity that is shaped in contrast to the hegemonic imaginary of national identity. This paper aims at establishing dialogues between archaeological interpretations and the acknowledgement and meanings attributed to cultural heritage, in comunas where museums were built in order to support the revitalization of national and local culture.
\end{abstract}

Key words: Heritage, identity, territory, communal, peninsular.

\section{El Legado de los Antepasados}

\section{“Ángeles somos del cielo venimos, pan pedimos"}

Las almas difuntas se "hacen sentir" entre los peninsulares cuando se observan "candelillas" en las noches y se sueñan los finados; es entonces cuando las familias se reúnen y se prepara la Mesa de los difuntos con comidas que en vida gustaban a los finados, convocándolos uno a uno rezando (Figura 1).

Solo en el tiempo de los muertos se sacan para la mesa mantelitos tejidos a mano, uno para cada finado, y las abuelas desempolvan los recipientes que están "santos" para los angelitos que vienen del cielo. Anticipadamente se hace pan y chicha de maíz para compartir con los muertos y entre los vivos que, cada 1 y 2 de noviembre, llegan diciendo "ángeles somos del cielo venimos, pan pedimos".

Es una de las tradiciones de la época de "los antiguos", que cada comunidad peninsular reclama como suya, en un mundo que se aleja cada vez más de la cosmovisión de sus antepasados. Esta manifestación ancestral ha permanecido en el tiempo como reconocimiento y referencia, en una dimensión simbólica significativa. Es un hecho colectivo de múltiples significados, una experiencia sagrada que da cuenta de la construcción de una particular percepción del mundo.

\footnotetext{
${ }^{1}$ Consultora independiente en Arqueología y Patrimonio, Ecuador. anamaritzafreire@yahoo.es
}

Recibido: enero 2018. Aceptado: diciembre 2018. 
A partir de la celebración en homenaje a los muertos se teje la memoria entre los peninsulares y les proporciona un sentido de identidad y continuidad.

En palabras de Karen Stothert:

Este es uno de los legados de los antepasados. Los habitantes peninsulares han rendido culto a sus muertos desde la época de las Cultura Las Vegas. Desde hace 8.000 años ya estaban preocupándose de tener a los muertos con ellos, dentro de su comunidad o de su hogar como parte de su identidad, y esta tradición antigua de toda América es parte de la creencia muy difundida de que todo el bienestar que necesitamos para vivir viene de los ancestros y para mantener el ciclo de la vida de los vivos, debemos mantener el flujo de comunicación con los muertos; eso implica dar de comer a los muertos para recibir luego lluvia, fertilidad y bienestar (Anchundia et al. 2009:16).

\section{Territorio ancestral}

Los peninsulares se reconocen en su territorio, un espacio de inscripción de un pasado y memoria colectiva, como símbolos de identidad socio territorial. Este territorio es producto de un milenario proceso, un espacio constituido por ancestrales tradiciones, pensamientos y conocimientos para la subsistencia.

A la llegada de los españoles, en el área peninsular se asentaron los Guancavilcas y al norte los Manteños; los indígenas sobrevivientes al impacto de la conquista fueron repartidos en el territorio bajo el sistema de encomiendas. Luego existió una "Provincia de los Guancavelicos" (o "Huancavilcas"), cuyo referente de autoridad era el señor de Colonche, pero que permaneció aislada de los "blancos" por la "separación residencial de españoles e indígenas, a los cuales se recluyó en las Reducciones" (Paz y Miño 2010).

Arqueológicamente los Guancavilcas se inscriben en un contexto cultural mayor denominado Manteño Guancavilca (650 - 1531 DC) que se extendió a lo largo de la franja litoral. Los pueblos de esta cultura y sus predecesores de las Culturas Las Vegas (6500 - 4600 AC), Valdivia (3500 - 1500 AC), Machalilla (1500 - 800 AC), Engoroy ( 800 - 300 AC) y Guangala (200 AC - 800 DC), dejaron evidencias de sus asentamientos, conocimientos agrícolas, navegación y manufacturas. Son recurrentes los hallazgos de materiales arqueológicos en el área, así como edificaciones, aterrazamientos, pozos y albarradas, testimonio de la transformación que hicieron del

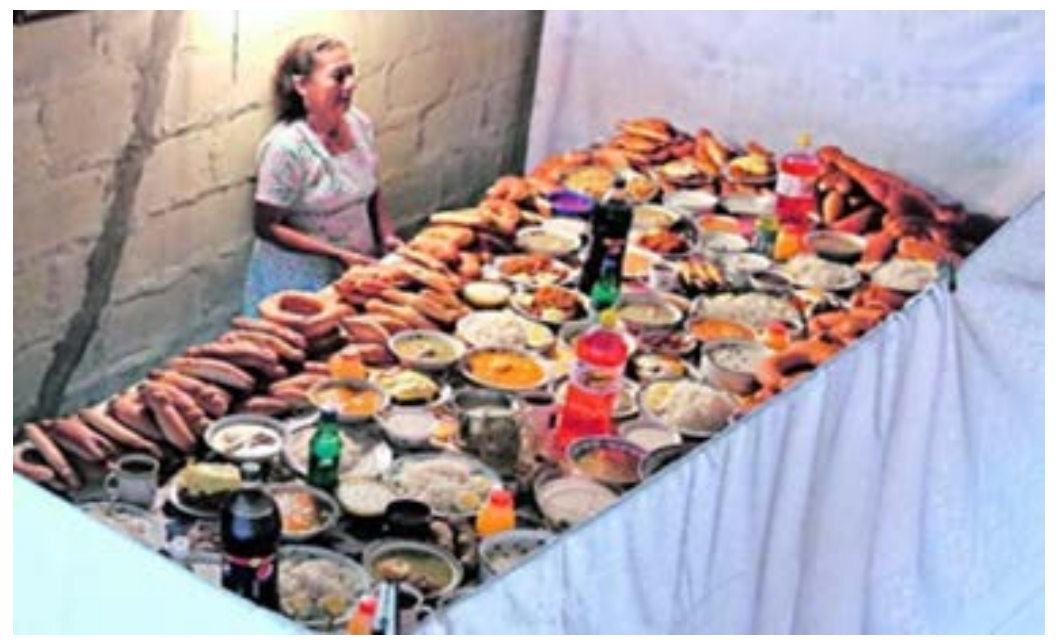

Figura 1. Mesa para los Difuntos.

Table for the Deceased. 
paisaje. Los saberes y tradiciones inmemoriales heredados de estos pueblos ancestrales, configuran la cultura actual de las poblaciones que habitan en el territorio peninsular (Freire 2010).

\section{Autonomía comunal}

Los peninsulares tienen una historia común de lucha por sus territorios. Las poblaciones asentadas en la Península de Santa Elena mantuvieron una autonomía territorial hasta constituirse, a parir de 1937, en las actuales Comunas reconocidas por el Estado ecuatoriano con la expedición de la Ley de Régimen y Organización de Comunas. Estas instituciones legales, son la resultante del fraccionamiento territorial de las antiguas comunidades indígenas coloniales asentadas en el área. Dicho proceso se contrapone a la generalizada idea de pasividad y retracción que se asigna a la población indígena o la de su temprana desaparición (Álvarez 1991).

Desde la colonia los peninsulares consolidaron la autonomía territorial que los diferenciaba de la mayoría de indígenas sometidos en las haciendas de la zona interandina. En su política de negociación consiguieron que el intercambio y el continuo contacto con la sociedad dominante, no produjera una total asimilación. Se articularon con ella pero conservaron una identidad diferencial que se ha mostrado dinámica y cambiante.

Los pueblos indígenas de la costa ecuatoriana fueron declarados mestizos "aculturados", "campesinos", sin derechos al reconocimiento étnico. La visión "andinocéntrica" invisibilizó a los comuneros peninsulares.

Lo grave en las idealizaciones del pasado indígena local es que los indígenas vivos, organizados en comunas y con dominio político todavía sobre amplios territorios geográficos, son ignorados y omitidos en sus particularidades étnicas. Esto se aprecia tanto en los proyectos de desarrollo como en las las propuestas políticas de regionalización administrativa de la provincia, que eluden el reconocimiento de la diversidad cultural a su interior. Se puede eliminar socialmente la capacidad de acción de un grupo al marginarlo a la no existencia, al reducirlo cuantitativamente a la calidad de minoría, al desconocerlo como parte del conjunto social y al cuestionar su identidad cultural (Álvarez 2004:278).

En el proceso de autoreconocimiento de los comuneros como "cholos" peninsulares, ha sido un reto desarrollar espacios de participación y representación política y social, por lo que la capacidad de organización se constituye en la base principal y en la proyección de la sociedad comunal.
Desde la estructura organizativa se defiende un proyecto colectivo fundamentado en relaciones de protección, reciprocidad y solidaridad comunal.

En la Península de Santa Elena hay 64 comunas, con un territorio de más de 515.000 ha. Estas organizaciones sociales de carácter étnico legalizadas como comunas, reconocidas como poder local, coexisten y se articulan a otros estamentos sociales. Ejercen el control y la gestión de su territorio, los recursos naturales, la infraestructura social y su patrimonio cultural.

La autopercepción de un nosotros sustentado en un pasado en común, construye una concepción de identidad entre los comuneros peninsulares. El carácter colectivo de la identidad cultural ha permitido garantizar la continuidad en el tiempo de la sociedad comunal definiendo quiénes son, quiénes comparten y se reconocen en su patrimonio.

\section{Legado prehispánico}

En las comunas peninsulares los habitantes se perciben a sí mismos como integrantes de una colectividad, se sienten identificados con los demás miembros, asumen un origen común, un territorio compartido, un patrimonio cultural como legado, al cual quieren salvaguardar.

El acervo prehispánico es parte del contexto de vida actual en las comunas donde se identificaron hallazgos arqueológicos y se desarrollaron proyectos de investigación científica, producto de lo cual se ha logrado nuevos conocimientos históricos.

En este sentido, la comuna se asume como depositaria de un patrimonio cultural que le ha sido heredado por generaciones precedentes, en torno al cual forjan una identidad colectiva diferenciada que se configura en una identidad local, articulada al imaginario sobre la identidad nacional.

\section{Museos e Identidad}

Los museos han tenido el rol de poner en valor el patrimonio en la construcción social de sentidos, narrativas e identidades locales, pues creen en su misión como parte del proceso de activación social en las comunidades. El patrimonio articulado al saber arqueológico en los museos construye un pasado cultural a partir de su presentación espacial y cronológica. Como parte de su discurso, los objetos son clasificados y mostrados de acuerdo a metodologías e interpretaciones, que a través de las exposiciones presentan una versión del pasado.

Los museos materializan las representaciones de la identidad, haciendo uso del patrimonio cultural reconocido por las comunidades. 
Este espacio ha propiciado el diálogo en el campo de la educación, investigación, producción y difusión del patrimonio, a través de prácticas que apuntalan las economías creativas, artesanías y turismo.

Los museos han sido de interés local, tienen un papel en la construcción de la memoria social y la reflexión colectiva, y han buscado ser parte de los procesos de desarrollo comunal.

Tanto el museo y la arqueología nacional como la gestión de patrimonio cultural, se entienden como dispositivos de la memoria en la medida en que funcionan como mecanismos de reconstrucción del pasado. El planteamiento del museo es la mirada de la historia. El museo actúa directamente sobre el establecimiento de una noción del pasado a través de su representación material y visual. Saber y patrimonio confluyen en el espacio museo, pues se instituye como un instrumento socializador (Calero 2010).

\section{Museos Locales}

En el territorio peninsular existen siete museos relacionados con vestigios arqueológicos en áreas comunales; en unos casos son museos de sitio, en otros son museos de la arqueología local y dos son instalaciones museográficas al aire libre. Se incluyen también dos museos contiguos al territorio peninsular por estar vinculados históricamente, además de presentar una problemática socio cultural y territorial de similares características.

La creación de estos museos se ha centrado en la presentación de procesos productivos, sociales y rituales de las sociedades precolombinas, en los que prevalece la interpretación basada en la investigación científica. En su planteamiento han venido considerando también las percepciones, significados y valores adjudicados al patrimonio por los pobladores y actores sociales locales, fortaleciendo los procesos de sensibilización y concienciación respecto del patrimonio.

Los museos que se presentan en este trabajo (Tabla 1) se agrupan de acuerdo a las perspectivas que los proyectos se plantearon ante y desde las comunidades, presentando el contexto particular en que se desarrolló la investigación arqueológica y la gestión cultural.

El objetivo es esbozar los efectos que esos procesos tuvieron sobre la comunidad en lo concerniente a su dinámica socio cultural, ya que se dieron en un contexto específico donde operaron políticas públicas, la academia, actores políticos y culturales. Si bien no es la ocasión para adentrarnos en la problemática

Tabla 1. Museos en la Península de Santa Elena.

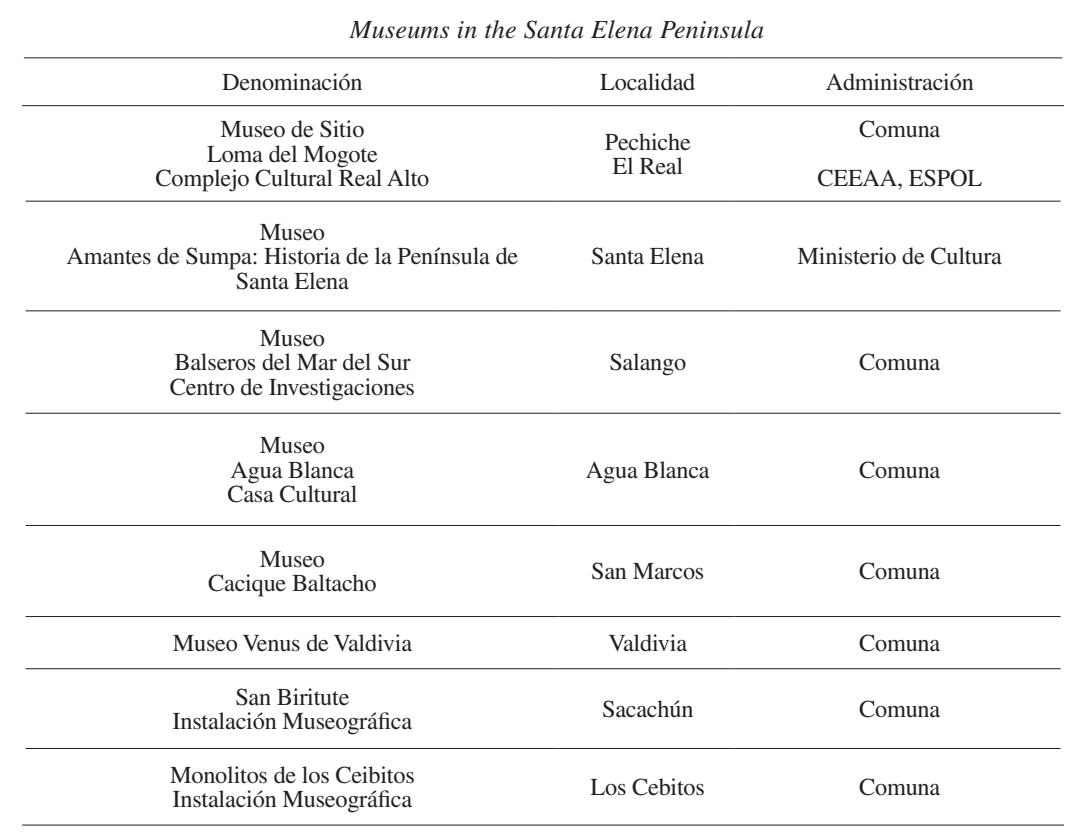


cultural y patrimonial de cada localidad, lo que si podemos es respondernos sobre qué tipo de consecuencias tuvo la investigación arqueológica y la creación de museos, así como en qué medida éstos les conciernen a la comunidad.

\section{Las investigaciones científicas en la Península de Santa Elena y la revalorización identitaria: Real Alto y Amantes de Sumpa}

Los resultados de las investigaciones científicas en los sitios arqueológicos de la península, y principalmente de los sitios Real Alto y Las Vegas, han contribuido con conocimientos e interpretaciones del pasado para la revalorización de lo "cholo peninsular", sentando las bases de una memoria histórica propia y la autoconciencia de la identidad local.

\section{Museo de Sitio Loma del Mogote: Complejo Cultural Real Alto}

Las investigaciones arqueológicas de Real Alto ha establecido que el sitio constituye una de las primeras aldeas con agricultura y cerámica (3500 - 1500 AC), contribuyendo a entender el proceso de neolitización en el continente americano. El sitio fue reportado en 1971 por Jorge Marcos y excavado inicialmente por Donald Lathrap y su equipo de investigadores de la Universidad de Illinois. Posteriormente desarrollo investigaciones el Centro de Estudios Arqueológicos y Antropológicos (CEEAA) de la Escuela Superior Politécnica del Litoral (ESPOL) (Figura 2).
Los estudios científicos han permitido reconstruir la organización socio económica alcanzada por la sociedad Valdivia, los cambios en el patrón de asentamientos y la compleja organización sociopolítica que se gestó durante 1.400 años de ocupación continua del yacimiento.

El Complejo Cultural Real Alto está conformado por el museo denominado "El Mogote", una vivienda etnográfica, un huerto experimental y un área de laboratorios. En su recorrido, el museo presenta de manera didáctica el proceso histórico de la Santa Elena, desde las evidencias de los antiguos habitantes hasta la persistencia actual de tradiciones culturales (Figura 3).

\section{Museo Amantes de Sumpa: Historia de la Península de Santa Elena}

Los sitios de la Cultura Las Vegas constituyen la adaptación cultural más antigua que se conoce en el Ecuador, entre 6000 - 4600 AC. Durante las investigaciones se encontró un cementerio con más de 200 osamentas que evidenció distintas prácticas funerarias, incluyendo el entierro de una pareja que se conoce como Amantes de Sumpa. La gente de Las Vegas eran cazadores recolectores que agregaron plantas cultivadas a su sistema de subsistencia (Stothert 1988).

El museo hace referencia a los antiguos pobladores de la Península de Santa Elena (Figura 4). La exposición presenta evidencias de las formas de vida de las culturas Las Vegas, Manteña, Guangala, Engoroy y

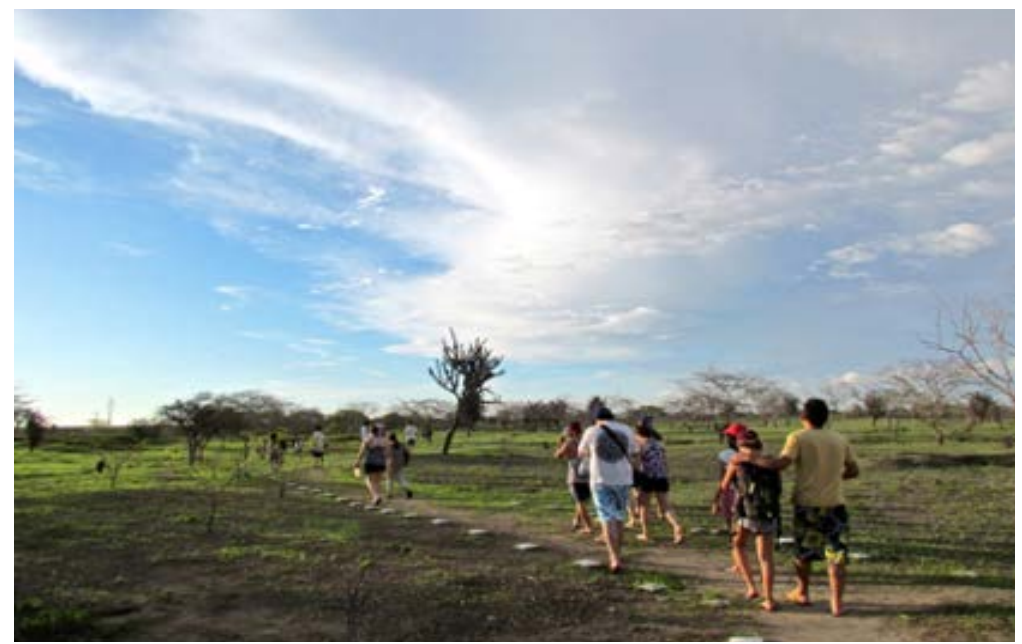

Figura 2. Sitio Real Alto.

Real Alto site. 
Valdivia. También se muestra la historia peninsular pasando por las etapas colonial y republicana, para conocer cómo las comunidades indígenas aprovecharon las innovaciones y conservaron su modo de vida (Stothert y Freire 1997).

Complementariamente hay una vivienda de arquitectura vernácula que recrea las áreas de uso cotidiano, con taller de sombreros de paja toquilla y tejido con telar vertical, así como un taller de fundición y hornos de barro en el exterior. Se trata de un espacio creado para mostrar conocimientos y técnicas inherentes a prácticas artesanales tradicionales.

\section{Investigación y significado social}

El valor del patrimonio cultural en los poblados donde se levantan estos dos museos radica en el reconocimiento conferido a los vestigios arqueológicos. Con el desarrollo de las investigaciones y la difusión de los resultados, los sitios arqueológicos empezaron

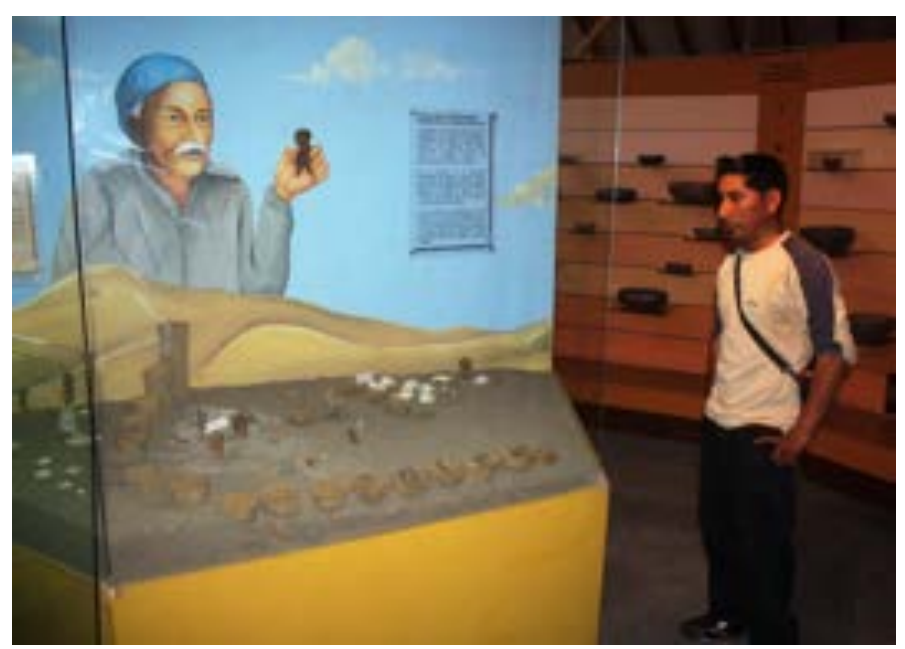

Figura 3. Museo de Sitio Loma del Mogote. Complejo Cultural Real Alto.

Loma del Mogote site museum. Real Alto cultural complex.

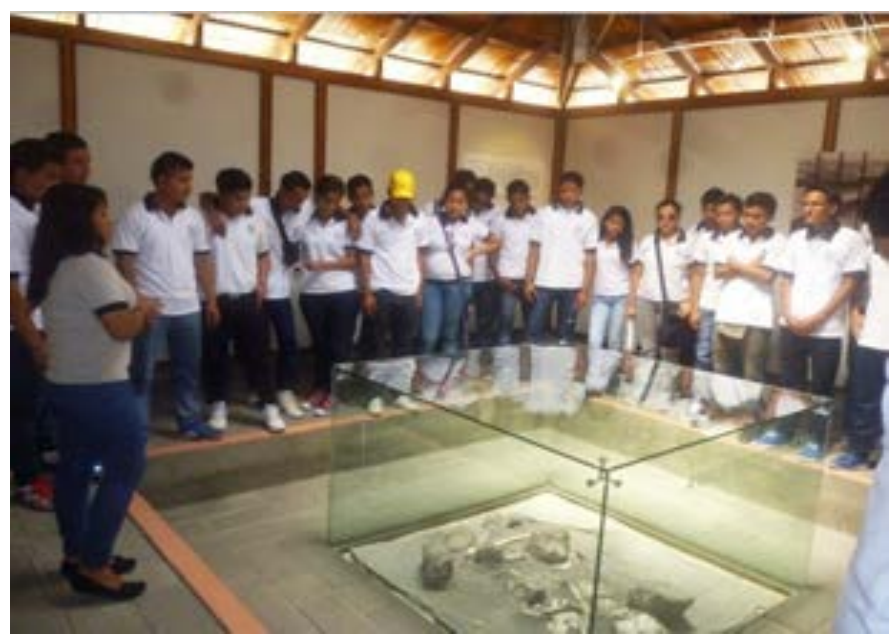

Figura 4. Museo Amantes de Sumpa: historia de la Península de Santa Elena.

Amantes de Sumpa Museum: history of Santa Elena Peninsula. 
a adquirir significado local, desarrollándose un sentido de pertenencia entre los pobladores.

Los componentes arqueológicos de los museos son tanto los objetos tangibles como las reconstrucciones de los contextos de hallazgo, sea doméstico, productivo, ritual o funerario, y es en función de éstos que los bienes culturales adquieren sentido. Textos, imágenes y objetos presentan aspectos del desarrollo histórico que han sido interpretados científicamente.

Araízdelaconstitución deestos museos seestimuló la utilización, entre actores culturales y pobladores, de imágenes basadas en el arte precolombino: vasijas, figurinas, diseños precolombinos y, particularmente, el entierro de Los Amantes de Sumpa, que ha suscitado también una nutrida producción literaria y de artes escénicas. Esto pone de manifiesto la reivindicación del carácter ancestral, cobrando las imágenes nuevos sentidos en el contexto local actual, contribuyendo a construir una identificación cultural.

Ambos museos se han convertido para los pobladores en espacios de relación con la vida social y las costumbres étnicas. La conmemoración del día de los muertos con la presentación de mesas de difuntos, es una actividad cargada de sentido cultural y orgullo por la herencia cultural.

Los museos expenden trabajos en tejidos, metales y cerámica, que también se exhiben como testimonio de la producción local artesanal vinculada a un sentido identitario. Son un medio de promoción y desarrollo para las comunas de la Península de Santa Elena.

El funcionamiento de talleres vivos permite reproducir saberes ancestrales entre los pobladores en interacción con su tradición e historia, infundiéndoles un sentimiento de continuidad y contribuyendo a promover en el visitante el respeto por la creatividad humana y la diversidad cultural.

\section{El Patrimonio Cultural dentro del Contexto de la Protección Ambiental: Salango y Agua Blanca}

En las comunas de Agua Blanca y Salango la gestión del patrimonio cultural se funde con la protección ambiental, defendiendo lo que se considera como propio. En este sentido, la salvaguarda de los recursos culturales y el cuidado del ambiente se enmarcan en la lógica de la tradición de lucha por el territorio comunal. La patrimonialización de la naturaleza y la cultura, que ha tenido como inductor el Parque Nacional Machalilla, ha significado la defensa de su espacio y los recursos para la subsistencia.

\section{Museo Balseros del Mar del Sur. Centro de Investigaciones}

El museo arqueológico de Salango y su centro de investigación nacieron con el Programa de Antropología para el Ecuador, dirigido por Presley Norton (Figura 5). En la localidad se identificó un sitio multicomponente con seis ocupaciones culturales identificadas: Valdivia, Machalilla, Chorrera, Bahía, Guangala y Manteño. Las investigaciones arqueológicas (Norton et al.1984) determinaron que los habitantes precolombinos del sitio aprovecharon los recursos del mar, logrando configurarse como señoríos que habrían practicado el comercio a larga distancia. Salango ha sido definido como un centro

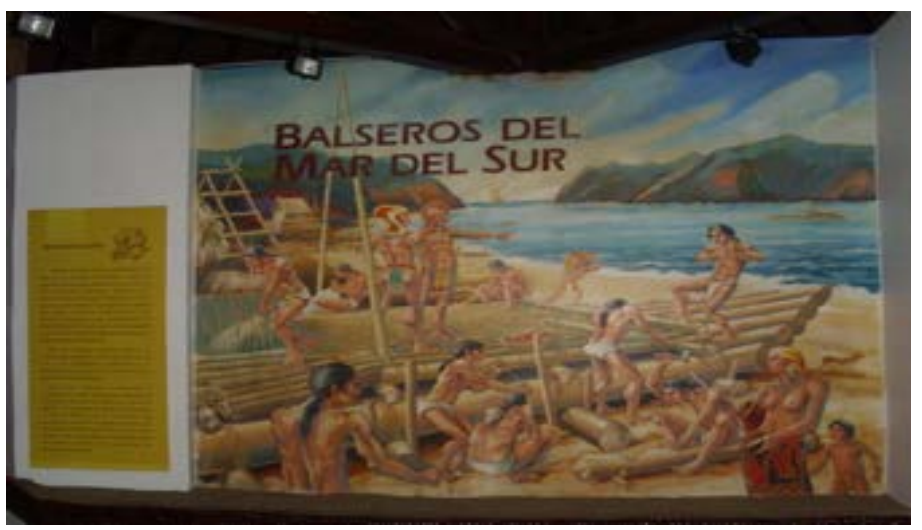

Figura 5. Museo Balseros Mar del Sur.

Balseros del Mar del Sur Museum. 
ceremonial en el que se procesaron cantidades de concha, teniendo cerca la Isla de la Plata, así como adoratorio y puerto de redistribución de la concha sagrada Spondylus.

La ocupación prehispánica más tardía es la de los manteños, que se caracterizaron por ser expertos navegantes. Practicaban el comercio intensivo con otros pueblos precolombinos gracias a embarcaciones elaboradas con madera de balsa. Jijón y Caamaño (1945) se refirió a ellos como pertenecientes a una "Confederación de Mercaderes del Sur", comerciantes navieros que llegaban a Perú y México, llevando mullos elaborados con concha Spondylus y objetos de oro, plata, cobre y obsidiana. En el primer contacto español con los navegantes, la crónica Sámano-Jerez (1527) describe la captura de una balsa proveniente del puerto de Salango (Norton 1992:4).

La balsa tiene una representación actual en el contexto de la celebración de un festival cultural que se realiza cada 12 de octubre (Figura 6). La actividad moviliza recursos desde el turismo, convirtiendo relaciones de mercado en relaciones sociales e identidad cultural. Se convirtió en un compromiso colectivo que conmemora la persistencia cultural, fortalece lazos de ayuda recíproca y produce la integración social.

\section{Museo Agua Blanca. Casa cultural}

Agua Blanca se ubica en el corazón del Parque Nacional Machalilla y tanto el museo como el sitio arqueológico se hallan administrativamente bajo la custodia de la comuna (Figura 7).

\section{Gestión Comunitaria y Rescate Arqueológico: San Marcos de Colonche}

En 1998 se dio a conocer el hallazgo de objetos arqueológicos en la comuna de San Marcos de Colonche, que quedaron al descubierto a consecuencia de las intensas lluvias causadas por El Niño, despertando el interés de los comerciantes de piezas. A pedido de la comuna y con la participación de la población local, se realizó un rescate arqueológico en el que se descubrieron 14 tumbas y se pudo establecer que se trataba de una ocupación tardía.

Según la arqueóloga Stothert, los restos corresponden a los antiguos pobladores de San Marcos, poco antes de la llegada de los españoles, y que formaban parte del cacicazgo de Colonche.

Al respecto, Girolamo Benzoni (2000 [1572]) en sus relatos La Historia del Mondo Novo (15471550), describe:

Pasados los límites de la provincia de Porto Viejo, se entra al país de los Guancavilcas, cuyo primer pueblo que se encuentra en el camino se llama Colonchi, ubicado cerca a la Punta de Santa Elena. Yo he visto varias veces al señor de este pueblo que podía tener la edad de sesenta años y era de aspecto verdaderamente señorial; tenía el cuerpo robusto y sanísimo; iba vestido con una camisa sin mangas, teñida de rojo y al cuello llevaba un collar de seis vueltas, de oro finísimo... Cuando los españoles ingresaron a estas tierras, las dominaba un señor llamado Baltacho, muy honrado y que ejercía tanta autoridad sobre sus vasallos que cuando alguien iba a visitarlo nunca se ponía de pie, a menos que divisara la persona de Colonchie.

A partir del conocimiento de este relato, comprendiendo el valor y el significado de los hallazgos arqueológicos, los comuneros se apropiaron de él y se volvió una motivación de carácter identitario, generando imágenes de ambos caciques, el de Colonchie en Colonche y el de Baltacho en la comuna de San Marcos.

\section{Museo Cacique Baltacho}

El museo fue edificado por gestión ante la Municipalidad del Cantón Santa Elena. Ubicado junto al sitio arqueológico investigado por Stothert, presenta una particular forma de vasija en posición horizontal, diseñada por los comuneros (Figura 8). En su interior se exhiben los objetos recuperados en las excavaciones de rescate, con sus descripciones e interpretaciones y la imagen del Cacique Baltacho pintada y modelada en cerámica.

En la Iglesia Parroquial de Santa Catalina de Colonche se instaló el Museo Alfred Enhjod, donde unas pocas piezas arqueológicas, junto al retrato del cacique de Colonche, remiten a los visitantes a su pasado prehispánico en medio de los objetos de la parafernalia ritual católica.

Aunque las investigaciones arqueológicas y este museo surgieron en medio de la negligencia y del saqueo, ahora son evidencia de la fuerza de lo local para mantener un espacio identitario con vida. El museo es manejado por los comuneros y allí radica su valor, por ser comunitario y participativo.

\section{Revalorización comunal}

Las imágenes de los caciques han servido a los pobladores como referencia sobre su carácter ancestral, asumiéndose como sus descendientes directos, por lo que han acompañado los procesos de gestión sociocultural generados desde la organización local. 


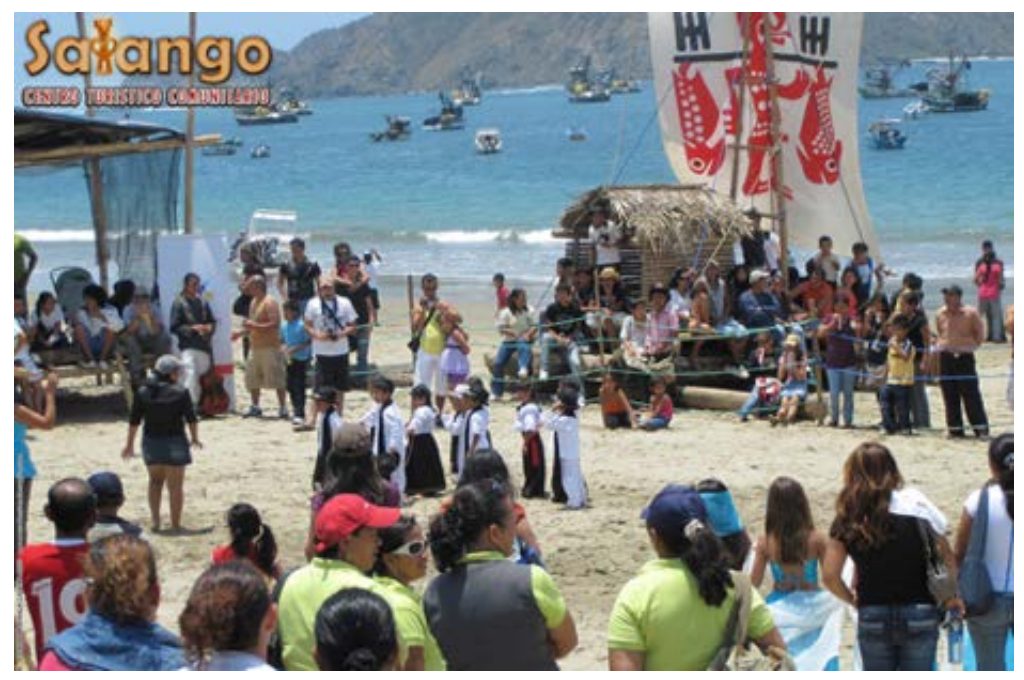

Figura 6. Festival de la Balsa.

Festival of the Raft.

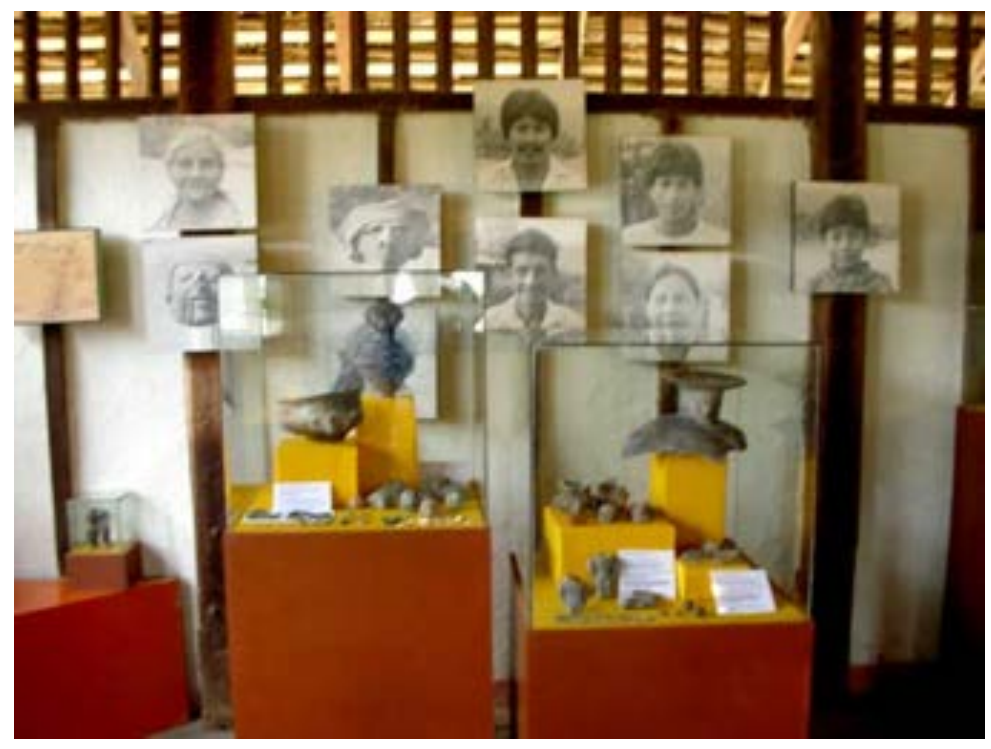

Figura 7. Museo Agua Blanca. Casa cultural.

Agua Blanca Museum. Culture House. 
Los objetos arqueológicos recuperados en la investigación y que permanecen en el museo tienen un gran significado arqueológico, pero es superado por la trascendencia de los sentidos identitarios que adquirieron. La organización comunal vetó en su momento las excavaciones ilícitas y el mercado de piezas. Por otro lado, aún sabiendo la rentabilidad que podría presentar el turismo, no han querido volver el patrimonio en un objeto de consumo para no caer en las prácticas culturales reducidas a espectáculos turísticos, que no dan el valor y el significado que ellos le confieren. Con limitaciones, han ido asumiendo la conservación y revalorización de este legado cultural con estrategias de gestión adecuadas y en beneficio del desarrollo socioeconómico propio.

\section{La referencia de los orígenes ecuatorianos: Valdivia}

Los hallazgos arqueológicos de Emilio Estrada en Valdivia, volcaron el interés en esta localidad y en la arqueología del Formativo en Ecuador (Estrada 1956; Evans y Meggers 1966). Valdivia se convirtió en la referencia de los orígenes de los asentamientos humanos en el país, donde hay evidencias de alfarería temprana y la creación de figurinas antropomorfas femeninas. El sitio arqueológico fue declarado como Patrimonio Cultural de la Nación en el año 1997, con un área protegida que abarca $13,000 \mathrm{~m}^{2}$.

\section{Museo Venus de Valdivia}

Luego de las investigaciones en la zona, y como una forma de impulsar el turismo y la conservación arqueológica, en 1974 nació la idea de crear un museo de sitio (Figura 9). Sin embargo, desde esos años hasta el presente han sido varios los intentos infructuosos por mantener una exposición relacionada con las evidencias encontradas.

Con los estudios de la cultura Valdivia, y a partir de la cronología cultural planteada por Estrada, surge una nueva manera de representar el pasado. Su descubrimiento replanteó el origen de la ecuatorianidad y puso en la palestra al Ecuador como cuna de la civilización cerámica más antigua de América.

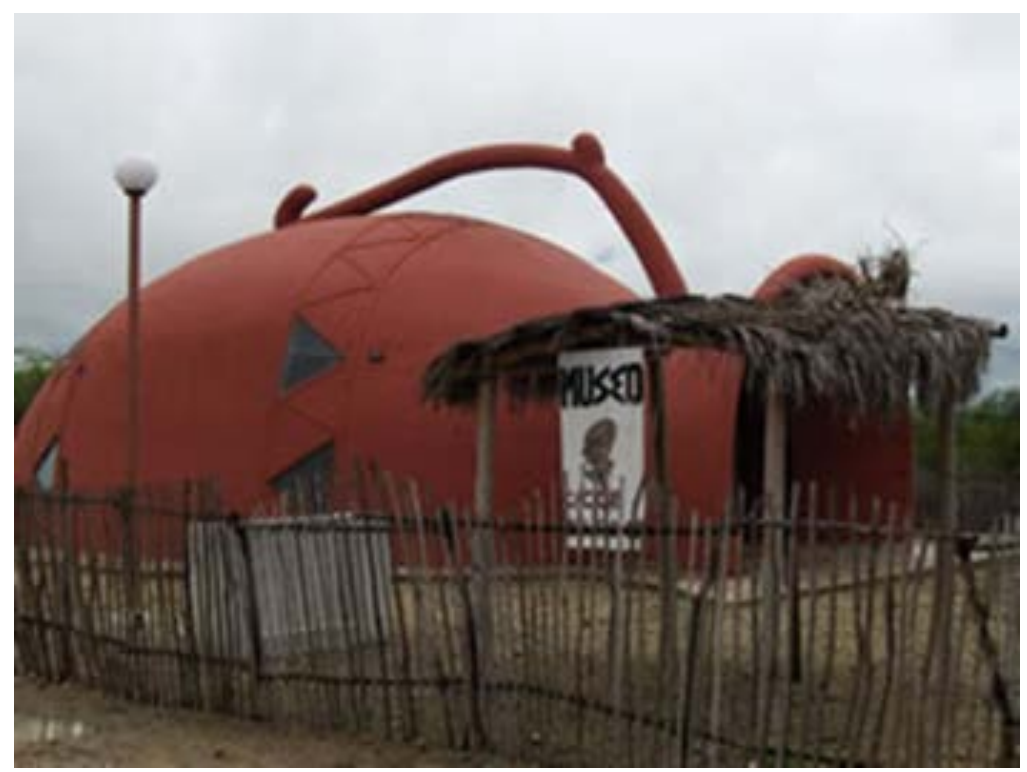

Figura 8. Museo Cacique Baltacho.

Cacique Baltacho Museum. 
A partir del descubrimiento inició un proceso de valoración de las figurinas como objetos icónicos, convirtiéndose en motivo recurrente de interpretación y símbolo del descubrimiento arqueológico. Los pobladores encontraron en las figurinas una especie de génesis en el discurso de indigenización de sí mismos, al declararse descendientes directos de la cultura Valdivia. El discurso sobre la ancestralidad de los "pueblos originarios" ha sido apropiado y reproducido estratégicamente por los pobladores de esta comuna para su propio beneficio.

\section{Representaciones visuales y mercado}

El hallazgo arqueológico es el hecho más significativo dentro de la historia local pues situó en el mapa a este pequeño poblado desconocido. $\mathrm{Si}$ bien se ha establecido un comercio de manufactura de réplicas, particularmente de figurinas (Figura 10), ello no ha repercutido en el desarrollo local. Podría decirse que, simbólicamente, la figurina
Valdivia reprodujo su fertilidad en el mercado (Vacas y Balanzátegui 2010).

Las figurinas no solo están presentes en monumentos, ilustraciones, logotipos y en las tiendas de réplicas artesanales, sino también en espacios cotidianos. Constituyen una forma de identidad, de apropiación y uso local del objeto arqueológico, de su valor histórico dentro de un contexto de reconocimiento étnico. Para la antropóloga Carolina Calero (2010:105):

Si bien la revalorización de la Figurina Valdivia pudo haber sido introducida externamente a la localidad, se constituyó y se constituye como un auto-referente, y por lo tanto, un mecanismo estratégico de identificación que reafirma una pertenencia identitaria y étnica de los pobladores de la comuna Valdivia. Este objeto apropiado y valorado de diversas maneras, hoy, para los pobladores es un ícono de carácter local y nacional, que evidencia la continuidad ancestral, los vínculos con lo prehispánico.

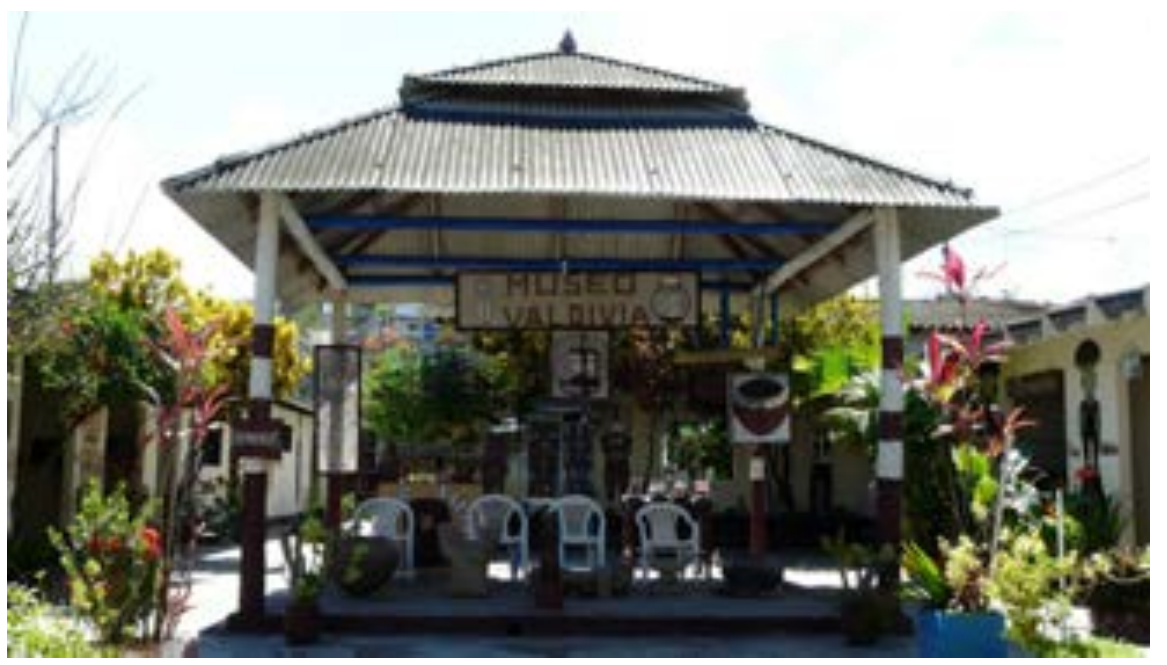

Figura 9. Museo Venus de Valdivia.

Venus de Valdivia Museum.

Se trata de una re-simbolización del ícono, presente ensu representación visual y material.

\section{Patrimonio restituido a la comunidad: Sacachún y Los Ceibitos}

La devoción a San Biritute fue cuestionada por la Iglesia católica y por ello fue sustraída. En esa época, se produjo en Sacachún un periodo de intensa sequía y la falta de lluvias fue asociada por los pobladores a la ausencia del monolito. Así, en 1993, la comunidad inició formalmente los pedidos de devolución, logrando el retorno del monolito el 16 de julio de 2011 (Figura 12).

En el sureste de la Cordillera Chongón Colonche, hay un viejo sistema de caminos hacia la costa a lo largo del cual están emplazados varios 
monolitos prehispánicos en el centro de cada localidad (Figura 11). Estas figuras emblemáticas revisten un gran significado por ser una manifestación de la cosmovisión aborigen y de sus descendientes actuales, pero fundamentalmente por estar intrínsecamente relacionadas con identidad de sus poseedores y la reivindicación de sus territorios e identidad de sus poseedores. Huerta Rendón estimó que tales figuras estaban interrelacionadas, por lo que denominó al trayecto la Ruta de los Viejos Dioses. Sus palabras fueron:

Raspad -nos atrevimos a escribir en 1949- la corteza superficial, hecha de conveniencias, temores y vacilaciones de muchos de los habitantes de y encontrareis, bajo el escapulario, el culto a los totems, la fe en las mismas divinidades que adoraron sus antepasados. Profundizad aún más, si podéis, y el aborigen, el huancavilca puro, aparecerá ante vuestro asombro (Huerta Rendón 1955:49).

\section{Monolito San Biritute}

El San Biritute es un monolito antropomorfo que luego de ser extraído por la fuerza de la comuna Sacachún, en 1952, fue exhibido en una de las calles de Guayaquil y luego formó parte de la colecciones arqueológicas del Museo Municipal. A pesar del tiempo transcurrido desde el rapto, en la memoria colectiva de los sacachuneños aún persistía el recuerdo de los favores ofrecidos y la comunidad no dejó de exigir su devolución.

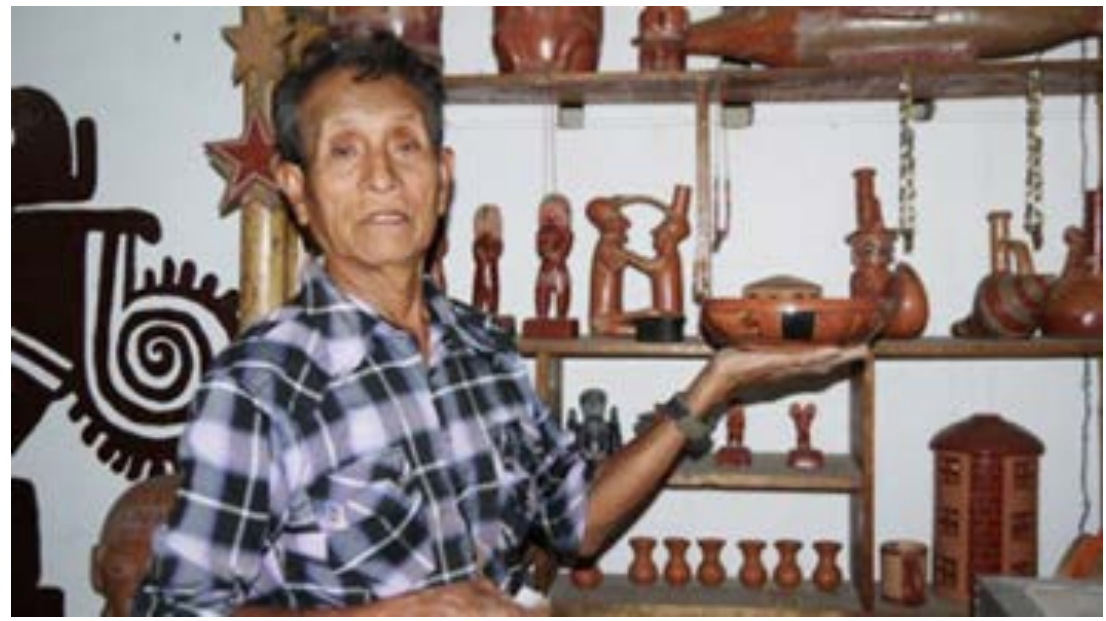

Figura 10. Juan Orrala, artesano de Valdivia.

Juan Orrala, craftsman from Valdivia.

La devoción a San Biritute fue cuestionada por la Iglesia católica y por ello fue sustraída. En esa época, se produjo en Sacachún un periodo de intensa sequía y la falta de lluvias fue asociada por los pobladores a la ausencia del monolito. Así, en 1993, la comunidad inició formalmente los pedidos de devolución, logrando el retorno del monolito el 16 de julio de 2011 (Figura 12).

Según el discurso oficial, la restitución de San Biritute a Sacachún constituye un gran paso hacia la recuperación de la memoria, identidad y patrimonio cultural de los pueblos peninsulares, al tratarse del primer elemento patrimonial que es devuelto a su comunidad de origen sobre la base de la Constitución de la República del Ecuador, reafirmando el compromiso del Estado de reconocer los derechos colectivos que garanticen las condiciones para el Buen Vivir de las comunidades, pueblos y nacionalidades indígenas.

El monolito es una figura tallada en conglomerado marino con el sexo explícito, razón por la cual se le 


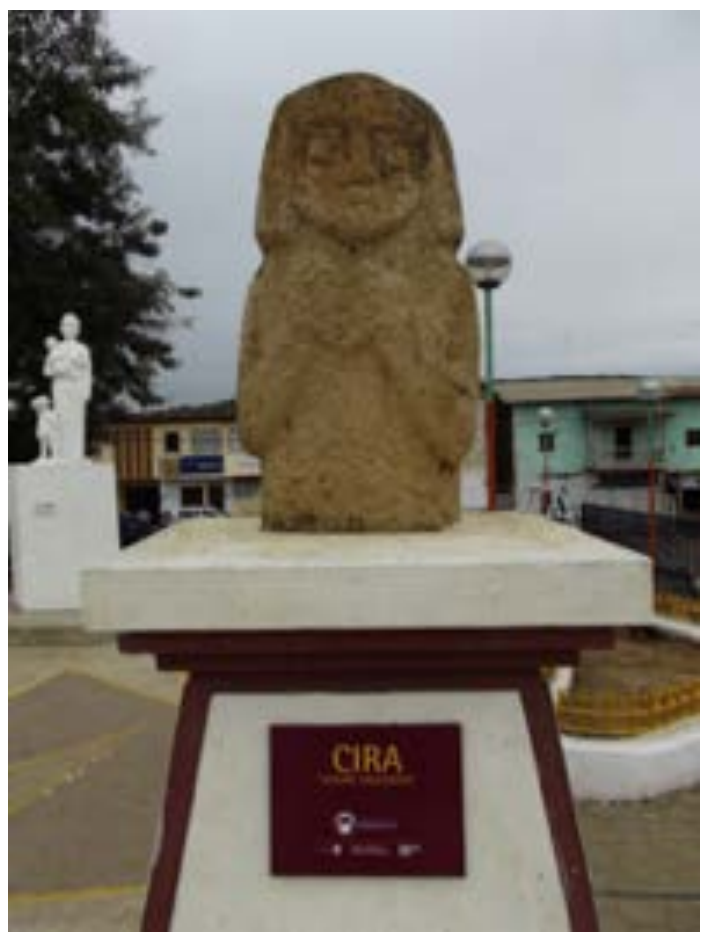

Figura 11. Monolito Cirila Madre Milenaria en La Barranca.

Monolith Cirila Madre Milenaria in La Barranca.

atribuyen poderes reproductores relacionados con la fertilidad, congregando prácticas rituales encaminadas a propiciar beneficios espirituales. Así como las esculturas de los santos católicos, el monolito forma parte de su espiritualidad y las dos simbologías persisten.

\section{Monolitos de Los Ceibitos}

A raíz del hallazgo de cuatro monolitos encontrados por recolectores de miel en el cerro Dos Tetas de la Cordillera Colon Colonche (Figura 13), se desarrolló un proyecto de investigación arqueológica por parte del Instituto Nacional de Patrimonio Cultural (INPC). Una de las esculturas representa a una figura masculina desnuda y de pie, que lleva en la cabeza un tocado de apariencia similar al de San Biritute.

La prospección en las cumbres del cerro reveló un patrón de asentamiento intensivo en las cimas planas, en casi todas de las cuales hay evidencias de la cultura Guancavilca. La excavación de 10 sitios permitió establecer de manera categórica la asociación de los monolitos a contextos funerarios, es decir, como marcadores o señaladores de tumbas.

Los comuneros participaron en las investigaciones prospectivas y las excavaciones. Una instalación

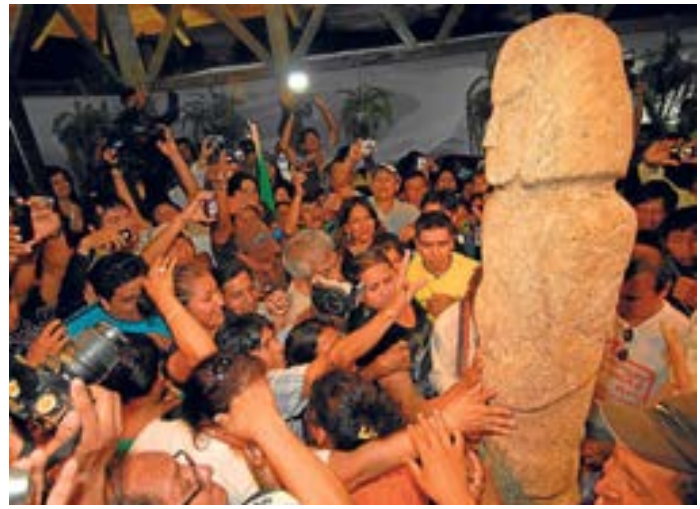

Figura 12. San Biritute.

San Biritute.

museográfica basada en el montaje de estos cuatro monolitos se encuentra en la Comuna de los Ceibitos, donde se espera por la construcción de un museo para promover el turismo comunitario (Figura 14).

\section{Reivindicación del patrimonio}

Los monolitos hasta la actualidad están estrechamente vinculados a diferentes prácticas rituales, otorgándoseles un contenido espiritual para propiciar la fertilidad y la vida, además de que confieren y validan sentidos sociales y políticos.

Desde la perspectiva de estos pueblos, cercanos a sus tradiciones orales y raíces culturales, los monolitos prehispánicos no son únicamente hallazgos de valor histórico: son la materialización del pasado y de su conexión directa con la tierra que habitan. $\mathrm{Al}$ respecto el arqueólogo Erick López afirma:

El nivel de comprensión de la problemática de los monolitos se va a situar dentro de un proceso de recuperación del territorio ancestral por parte de los descendientes de las antiguas comunidades de indígenas y esto básicamente sucede hacia finales del siglo XIX e inicios siglo $\mathrm{XX}$, donde se nota un proceso de redefinición de identidad, frente a una nueva situación que está siendo propiciada por el Gobierno central con el asunto de tierras comunales, que va a ir de la mano con necesidades petrolíferas, tratar de establecer latifundios de los centros urbanos de Guayaquil. En esta nueva perspectiva de reivindicación de territorios y de identidad ancestral había más conciencia de lo indígena, y se ve que están presentes en las comunidades 


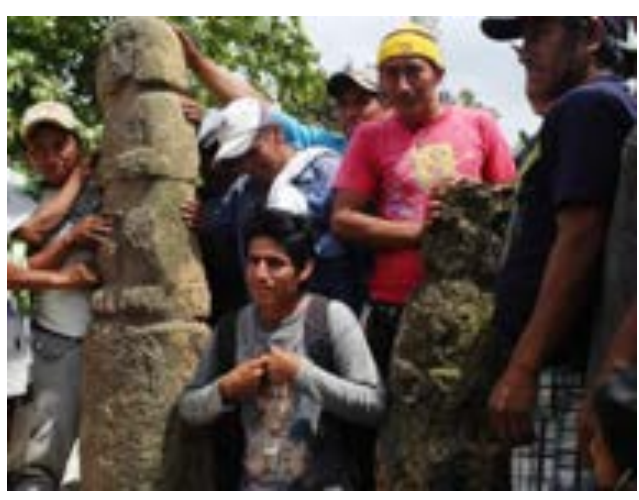

Figura 13. Hallazgo de los monolitos.

Discovery of the monoliths.

todos estos elementos de la cultura prehispánica de los ancestros Guancavilcas (Freire 2010:48).

En cada monolito y en cada localidad donde se despliegan, el pasado se manifiesta concienciando su valor identitario, haciendo memoria y constituyéndose en un legado para las futuras generaciones.

\section{Conclusión: Patrimonio Participativo}

El patrimonio arqueológico en la península se vincula fundamentalmente a una población organizada comunalmente en articulación con el contexto político y económico. Los aportes de la investigación científica para el conocimiento del pasado cultural han permitido fortalecer un discurso sobre la identidad a través de los museos. Las manifestaciones de identidad local se producido, en gran medida, a partir de la valoración de los objetos arqueológicos, sus imágenes y su interpretación.

La gestión del patrimonio en las comunas ha funcionado como mecanismo de reproducción de las identidades locales que, mediante procesos de legitimación, se convierten en referentes para la comunidad.

Los ejemplos aquí abordados muestran la necesidad de instrumentar proyectos de gestión patrimonial y cultural partiendo de las perspectivas, experiencias, problemáticas y requerimientos de los grupos locales. Este enfoque incluyente e integrador permite generar cambios sociales a partir de procesos participativos.

El tipo de museos con carácter comunitario involucran a organismos, actores sociales y al Estado, porque es ineludible vincular el patrimonio con los procesos sociales para que las comunidades se involucren la salvaguarda del patrimonio en sus territorios.

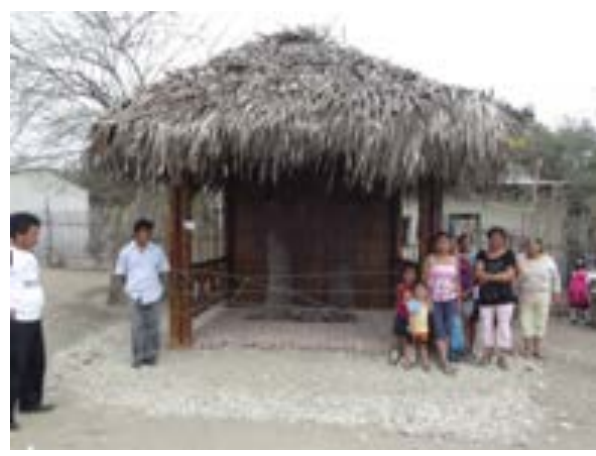

Figura 14. Monolitos exhibidos en Los Ceibitos.

Monoliths exhibited in Los Ceibitos.

A los investigadores les concierne participar en la puesta en marcha de propuestas museológicas elaboradas con base en sus resultados, insertándose en el engranaje de la comunidad. Porque entendemos al patrimonio como una asignación de valores con base en la investigación científica. Sin un vínculo de afinidad e identidad, no se logrará establecer el compromiso de reactivarlo y preservarlo para las generaciones venideras.

Para que los arqueólogos podamos contribuir en este proceso es necesario interactuar con la comunidad, así como con todos las instancias involucradas en la preservación del patrimonio y, por ende, en la reproducción del sistema de la gestión cultural.

Nuestros objetivos deben ser la puesta en valor de las particularidades socioculturales e históricas que descubrimos y reconstruimos a partir de nuestra labor, pero involucrándonos en la vida productiva y reproductiva de las comunas. En suma, se trata de socializar a través de los museos, potenciando el patrimonio, propiciando su impacto positivo entre los pobladores, vinculándonos a sus acciones, constituyéndonos de hecho como parte de los proyectos de desarrollo de cara al futuro comunal.

Agradecimientos: Al Instituto de Investigaciones Andinas (IAR), en la persona del Dr. Gary Urton y la Dra. Heather Lechtman, que hicieron posible nuestra participación en el Taller "Representaciones actuales de las culturas Pre-Colombinas en los Museos Andinos" (Sucre, Bolivia 5-7 de enero, 2017. A todos los participantes de la reunión, especialmente a Verónica Cereceda de ASUR, que dejaron sobre el tapete sus grandes enseñanzas, comprometidos como están con su trabajo. Y a aquellos peninsulares que, con su ejemplo de persistencia, volaron hasta los confines del altiplano boliviano. 


\section{Referencias Citadas}

Álvarez, S. 1991. Los Comuneros de Santa Elena. Tierra Familia y Propiedad. Biblioteca de Ciencias Sociales Vol. 34. Corporación Editora Nacional - Editorial Abya-Yala, Quito.

Álvarez, S. 2004. Organización social, cultura y gestión de los Sistemas de Albarradas en la PSE. En Las Albarradas en la Costa del Ecuador: Rescate del Conocimiento Ancestral del Manejo Sostenible de la Biodiversidad, coordinado por J. Marcos, pp. 253-365. CEAA-ESPOL, Guayaquil.

Anchundia, D., A. Freire y A. Pico 2009. Mesa de Difuntos: Espacio de Afirmación y Construcción Identitaria. Instituto Nacional de Patrimonio Cultural, Regional 5, Guayaquil.

Benzoni, G. 2000 [1572]. La Historia del Mondo Nvovo. Traducido por C. Radicati. Museo Antropológico del Banco Central del Ecuador, Guayaquil.

Calero, C. 2015. Representaciones Nacionales a Partir de la Producción, Circulación y Apropiación de Objetos Arqueológicos y Sus Imágenes. La Figurina Valdivia en el Campo Arqueológico, Institucional y Local. Tesis de Maestría. Departamento de Antropología, Historia y Humanidades. Facultad Latinoamericana de Ciencias Sociales Sede Ecuador, Quito.

Calero, C. 2011. San Biritute: representación simbólica del agua. Patrimonio Cultural Inmaterial 1 ( 29):10-11.

Espín, E. 2004. Diagnóstico de Los Rasgos Naturales Etnográficos y Antropológicos de la Comuna de Sacachún en la Península de Santa Elena Como Marco Para la Constitución de un Nuevo Producto Turístico. Tesis de grado. Facultad de Ingeniería Marítima y Ciencias del Mar. Escuela Superior Politécnica del Litoral, Guayaquil.

Estrada, E. 1956. Valdivia un Sitio Arqueológico Formativo en la Costa de la Provincia del Guayas, Ecuador. Museo Víctor Emilio Estrada 1, Guayaquil.

Estrada, E. 1958. Las Culturas Preclásicas Formativas o Arcaicas del Ecuador. Museo Víctor Emilio Estrada 5, Guayaquil.

Freire, A. 2013. Camino de los Dioses Guancavilcas. Instituto Nacional de Patrimonio Cultural Regional 5, Guayaquil.

Hidrovo, T. 2016. Tras Las Huellas de la Ciudad de Los Cerros. Corporación Centro Cívico Ciudad Alfaro, Montecristi.

Huerta Rendón, F. 1955. San Biritute, Señor de Zacachún. Contribución al estudio de la arqueología y del folklore de la provincia del Guayas. Cuadernos de Historia y Arqueología V:1314. Casa de la Cultura Ecuatoriana Núcleo del Guayas, Guayaquil.

Jijon y Caamaño, J. 1930. Una Gran Marea Cultural en el Noroeste de Sudamérica. Journal de la Societe des Americanistes 22:107-197.
Lathrap, D., J. Marcos y J. Zeidler 1986. Real Alto: un centro ceremonial agro alfarero temprano (Valdivia). En Arqueología de la Costa Ecuatoriana Nuevos Enfoques, editado por J. Marcos, pp.51-84. Corporación Editora Nacional, Quito.

Marcos, J. y T. Hidrovo 2010. Arqueología y Etnohistoria Del Señorío de Cancebí en Manabí Central. Editorial Mar Abierto, Manta.

McEwan, C. 1992. Sillas de Poder Evolución Sociocultural en Manabí - Costa del Ecuador. En 5000 años de Ocupación Parque Nacional Machalilla, editado por P. Norton, pp. 53-70. Centro Cultural Artes. Editorial Abya-Yala, Quito.

Meggers, B., C. Evans y E. Estrada 1965. Early Formative Period of Coastal Ecuador: The Valdivia and Machalilla Phases. Smithsonian Contributions to Anthropology 1, Washington, D.C.

Norton, P. 1992. Los Argonautas del Pacífico Oriental. En 5000 años de Ocupación Parque Nacional Machalilla, editado por P. Norton, pp. 1-9. Centro Cultural Artes. Editorial Abya-Yala, Quito.

Norton, P., R, Lunnis y N. Nailing 1984. Excavaciones en Salango, provincia de Manabí, Ecuador. Miscelánea Antropológica Ecuatoriana 3. Museo Antropológico del Banco Central del Ecuador, Guayaquil.

Paz y Miño, M. 2012. San Biritute: Lluvia, Amor y Fertilidad. Instituto Nacional de Patrimonio Cultural Regional 5, Guayaquil.

Ruiz, E. 2008. Agua Blanca Comunidad y Turismo en el Pacifico Ecuatorial. Editorial Abya-Yala, Quito.

Stothert, K. 1988. La prehistoria Temprana de la Península de Santa Elena, Ecuador: Cultura Las Vegas. Miscelánea Antropológica Ecuatoriana. Serie Monográfica 10. Museo Antropológico del Banco Central del Ecuador, Guayaquil.

Stothert, K. (ed.) 2001. Lanzas Silbadoras y Otras. Contribuciones de Olaf Holm al Estudio del Pasado del Ecuador. Tomo I. Museo Antropológico y de Arte Contemporáneo Banco Central del Ecuador, Guayaquil.

Stothert, K. y A. Freire 1997. Sumpa Historia de la Península de Santa Elena. Banco Central del Ecuador, Guayaquil.

Vacas, S. y D. Balanzátegui 2010. Estudios Culturales para la Difusión del Patrimonio Cultural en el Valle de Valdivia. Instituto Nacional de Patrimonio Cultural, Regional 5, Guayaquil.

Zevallos, C. 1995. Nuestras Raíces Huancavilcas. Casa de la Cultura Ecuatoriana, Núcleo del Guayas, Guayaquil. 
